đa số $(72 \%)$, nguyên nhân đau thắt lưng do nguyên nhân cơ học chiếm đa số (87,33\%).

2. Tỉ lệ bệnh nhân thuộc thể can thận hư kết hợp hàn thấp chiếm tỉ lệ lớn $(32,0 \%)$ thể huyết ứ chiếm $29,33 \%$; thể hàn thấp $15,33 \%$, thể can thận âm hư 3,34\%.

TÀI LIẸU THAM KHẢO

1. Trân Ngọc Ân (2002). Bênh thấp khớp - NXB Y hoc.

2. Nguyền Minh Giang (2015). Khảo sát các thể lâm sàng $Y$ học cổ truyền và tinh hình điều trị đau thắt lưng tại bênh viên $Y$ học cổ truyền trung ương, Luận văn tốt nghiệp bác sỹ y khoa, Đại học Y Hà Nôi

3. Trân Quốc Hùng, Nguyễn Thị Thanh Tú và công sư (2018), Khảo sát mô hình bênh tất và tình hinh điêu trị tai phòng Châm cứu ngoai trú bệnh viện đa khoa YHCT Hà Nội, Đề tài nghiên cứu khoa học cấp cơ sở năm 2018, Bệnh viện Đa khoa YHCT Hà Nội.

4. Nguyến Thị Ngọc Lan (2016), Bênh học cơ Xương khớp nội khoa, Nhà xuất bản giáo dục Việt Nam, tr 138 - 162.

5. Vũ Thị Thanh Thủy (2012), Chẩn đoán và điều trị những bệnh cơ xương khớp thường gặp, Nhà xuất bản Y học, Hà Nội, tr 56 - 64.

6. Trân Thị Đài Trang, Lê Thành Xuân, Trân Phương Đông (2018), Khảo sát phân thể lâm sàng và hiệu quá điều trị đau vùng thắt lưng tại Bênh viện Châm cứu Trung Ương, Tap chí Y học Việt Nam, tập 468; Tháng 7; Số 1; năm 2018, tr 155 - 159 .

7. Chou R, Qaseem A, Snow V et al. Diagnosis and treatment of low back pain: a joint clinical practice guideline from the American College of Physicians and the American Pain Society; Ann Intern Med 147 (7), 2007, tr 478 - 491.

\title{
ĐĂC ĐIỂM LO ÂU TRÊN THANG ĐIỂM GAD-7 Ở BÊNNH NHÂN UNG THƯ ĐƯờNG TIÊU HÓA TẠI BỆNH VIỆN K
}

\section{TÓM TẮT}

Mục tiêu: Đánh giá đặc điểm lo âu trên thang điểm GAD-7 ở bênh nhân ung thư đường tiêu hóa tai bệnh viện K. Đối tượng: 124 bệnh nhân đã chấn đoán xác đinh ung thư đường tiêu hóa và điều tri tai bênh viện $K$ từ tháng $8 / 2020$ đến tháng $10 / 2020$. Phương pháp: Nghiên cứu mô tả cắt ngang. Kết quả: Tỷ lệ nam/nữ là 2,6/1, tuổi trung bình là 57,9, đa số có trình độ dưới lớp $10(57,3 \%)$ và độc thân/góa (93,5\%). Vị trí ung thư phô biến nhất là đại trức tràng $(52,4 \%)$, tiếp theo là thực quản $(27,4 \%)$ và dạ dày $(20,2 \%)$, đa số ở giai đoạn III-IV $(64,5 \%)$. Điểm trung bình GAD-7 là 3,5 \pm 4,66 với 30,6\% bệnh nhân có lo âu. Lo âu có liên quan có ý nghĩa thống kê với tuổi $(\mathrm{p}=0,003 ; \mathrm{OR}=1,059,95 \% \mathrm{CI}=0,123-$ $9,097)$ và thời gian chẩn đoán ung thư $(p=0,037 ; O R$ $=1,238,95 \% \mathrm{CI}=0,140-10,940)$. Tỷ lề lo âu cao nhất ở ung thư dạ dày ( $20 \%$ có GAD-7 $\geq 10)$ và giai đoạn III-IV $(22,6 \%)$. Không có mối liên quan có ý nghĩa thống kê giữa lo âu với vị trí và giai đoạn ung thư ( $p>0,05)$. Kết luân: Lo âu thường găp ở người bênh ung thư đường tiểu hóa. Có mối liên quan có ý nghĩa thống kê giữa lo âu với tuổi và thời gian chẩn đoán bệnh.

Tư khóa: Lo âu, ung thư đường tiêu hóa, đặc điểm, PHQ-9.

\section{SUMMARY}

THE CHARACTERISTICS OF ANXIETY WITH

${ }^{1}$ Bênh viên $K$ cơ sở Tân Triều

Chịu trách nhiệm chính: Nguyễn Tiến Quang

Email: ntienquangbvk@gmail.com

Ngày nhận bài: 8.3.2021

Ngày phản biên khoa họ: 27.4.2021

Ngày duyệt bài: 10.5 .2021

\section{Nguyễn Tiến Quang1}

\section{THE GAD-7 IN GASTROINTESTINAL}

CANCER PATIENTS AT K HOSPITAL

Objective: To assess the characteristic of anxiety with GAD-7 in patients with gastrointestinal cancers at K hospital. Subject: 124 patients were diagnosed gastrointestinal cancer and treated at $\mathrm{K}$ hospital from August 2020 to October 2020. Methods: A crosssectional descriptive study. Result: The male/female ratio was $2.6 / 1$, the average age was 57.9 . The majority of patients had educational level under 10th grade $(57.3 \%)$ and were single/widowed $(93.5 \%)$. The most common cancer site was colorectal $(52.4 \%)$, followed by esophagus (27.4\%), and stomach $(20.2 \%)$, mostly at stage III-IV $(64.5 \%)$. The mean GAD-7 score was $3.5 \pm 4.66$ with $30.6 \%$ of patients having anxiety. Anxiety was statistically significant associated with age $(\mathrm{p}=0.003 ; \mathrm{OR}=1.059,95 \% \mathrm{CI}$ $=0.123-9.097)$ and time since diagnosis $(p=0.037$; $\mathrm{OR}=1.238,95 \% \mathrm{CI}=0.140)-10,940$ ). The highest rates of anxiety were in gastric cancer $(20 \%$ with GAD-7 $\geq 10$ ) and stage III-IV (22.6\%). There was no statistically significant relationship between anxiety and cancer site and stage $(p>0.05)$. Conclusion: Anxiety was common in patients with gastrointestinal cancer. There was a statistically significant association between anxiety and age and time since diagnosis.

Keywords: Anxiety, gastrointestinal cancer, characteristics, PHQ-9.

\section{I. ĐẶT VẤN ĐỀ}

Theo thống kê của GLOBOCAN năm 2020, tỷ lệ ung thư đường tiêu hóa ngày càng có xu hướng gia tăng, riêng ung thư đại trực tràng đứng thứ 3 vể tỷ lệ mắc mới (hơn 1,9 triệu người) và xếp thứ 2 về tỷ lệ tử vong (935.173 
ca) [1]. Chẩn đoán và điều trị ung thư không chỉ gây ảnh hưởng tiêu cực tới sức khỏe thể chất mà còn gây sợ hãi, lo lắng, căng thẳng cho người bênh. Theo NCCN, không thể cung cấp dịch vu chăm sóc ung thư toàn diện mà không giải quyết vấn đề tâm lý của người bệnh ung thư [2].

Lo âu được coi là bệnh lý khi không tương xứng với nguy hiểm thực tế hoặc gây cản trở cuộc sống bình thường của người bệnh, tỷ lệ gặp khoảng $30 \%$ ở bệnh nhân ung thư, đặc biệt ở nữ giới, trẻ tuổi [3]. Nghiên cứu đã chứng minh bệnh nhân ung thư đường tiêu hóa có triệu chứng lo âu có thể bị giảm thời gian sống thểm và chất lượng cuộc sống giảm đáng kể [4], [5].

Bộ câu hỏi GAD-7 (Generalized Anxiety Disorder 7-item) là một công cụ sàng lọc lo âu đơn giản và hiệu quả được sử dụng rộng rãi tại Việt Nam, tuy nhiên nghiên cứu áp dụng trên bênh nhân ung thư còn hạn chế. Nhằm mục đích xác định đặc điểm lo âu ở bệnh nhân ung thư đường tiêu hóa, từ đó giúp các nhà lâm sàng chẩn đoán kịp thời và điêu trị hiệu quả, chúng tôi thực hiện đề tài "Đặc điểm lo âu trên thang điểm GAD-7 ở bệnh nhân ung thư đường tiêu hóa tại Bệnh viện $K$ "nhằm làm rõ vấn đề này.

II. ĐỐI TƯỢNG VÀ PHƯƠNG PHÁP NGHIÊN CỨU

2.1. Đối tượng, địa điểm và thời gian: 124 bệnh nhân được chẩn đoán và điều trị ung thư đường tiêu hóa tại Bệnh viện $\mathrm{K}$ từ 08/2020 đến 10/2020 với:

- Tiêu chuân lứa chon: Bệnh nhân từ 18 tuổi trở lên được chẩn đoán và điều trị ung thư đường tiêu hóa tại Bệnh viện $\mathrm{K}$ cơ sở Tân Triều, có khả năng đọc hiểu nghiển cứu. Trong nghiên cứu này chúng tôi tập trung vào nhóm bệnh nhân ung thư ống tiểu hóa bao gồm ung thư thực quản, dạ dày, ruột non, đại tràng, trực tràng và ống hậu môn.

- Tiêu chuẩn loại trừ: Các bệnh nhân từ chối tham gia nghiên cứu, bệnh nhân có sa sút trí tuệ, chậm phát triển tâm thần.

2.2. Phương pháp nghiên cứu:

- Thiết kế nghiên cứu: Nghiên cứu mô tả cắt ngang.
- Các bước thu thập số liệu: Bệnh nhân đã được chẩn đoán và điêu trị ung thư được giải thích và mời tham gia nghiển cứu. Những bệnh nhân đồng ý sẽ thực hiện phiếu phỏng vấn gồm thông tin về tuổi, giới, trình độ văn hóa, tình trạng hôn nhân, vị trí ung thư và giai đoạn bệnh, sau đó thực hiện bộ câu hỏi GAD-7.

2.3. Xử lý số liệu: Số liệu được nhập và xử lý bằng phần mềm SPSS 20.0, sử dụng thống kê mô tả (\%, trung bình) và xác định mối tương quan bằng kiểm định Chi square với $\mathrm{p}<0,05$ được coi là có ý nghĩa thống kê.

\section{KẾT QUẢ NGHIÊN CứU}

3.1. Đặc điểm chung của nhóm đối tượng nghiên cứu

Bảng 3.1. Đặc điểm chung của nhóm đôi tượng nghiên cứlu

\begin{tabular}{|c|c|c|c|}
\hline \multicolumn{2}{|c|}{ Đặc điếm } & $\mathbf{n}$ & $\%$ \\
\hline \multirow{2}{*}{ Giới tính } & Nam & 90 & 72,6 \\
\hline & Nữ & 34 & 27,4 \\
\hline Tuối & Mean \pm SD & \multicolumn{2}{|c|}{$57,9 \pm 9,65$} \\
\hline \multirow{2}{*}{$\begin{array}{c}\text { Trình độ văn } \\
\text { hóa }\end{array}$} & Dưới lớp 10 & 71 & 57,3 \\
\hline & Từ lớp 10 trở lên & 53 & 42,7 \\
\hline \multirow{3}{*}{$\begin{array}{l}\text { Vị trí } \\
\text { ung thư }\end{array}$} & Thực quản & 34 & 27,4 \\
\hline & Dạ dày & 25 & 20,2 \\
\hline & Đại, trực tràng & 65 & 52,4 \\
\hline \multirow{2}{*}{$\begin{array}{l}\text { Giai đoạn } \\
\text { bệnh }\end{array}$} & I-II & 44 & 35,5 \\
\hline & III-IV & 80 & 64,5 \\
\hline $\begin{array}{l}\text { Điểm trung } \\
\text { bình GAD-7 }\end{array}$ & Mean \pm SD & \multicolumn{2}{|c|}{$3,5 \pm 4,66$} \\
\hline \multicolumn{2}{|r|}{ Tống } & 124 & 100 \\
\hline
\end{tabular}

Nhận xét: Trong 124 bệnh nhân nghiên cứu có $72,6 \%$ bệnh nhân nam và $27,4 \%$ bệnh nhân nữ. Tỷ lệ nam/nữ xấp xỉ 2,6. Tuối trung bình của đối tượng nghiên cứu là 57,9 tuổi. Có 57,3\% bệnh nhân có trình độ dưới lớp 10 và đa số độc thân hoặc góa (chiếm 93,5\%). Loại ung thư thường gặp nhất là đại trực tràng (chiếm $52,4 \%)$, tiếp theo là ung thư thực quản $(27,4 \%)$ và ít nhất là dạ dày $(20,2 \%)$. Đa số bệnh nhân ở giai đoạn III-IV (chiếm 64,5\%). Điểm trung bình GAD-7 là $3,5 \pm 4,66$ với 30,6\% có lo âu.

3.2. Mối liên quan giữa lo âu và đặc điểm chung

Bảng 3.2. Mối liên quan giữa lo âu và đặc điểm chung

\begin{tabular}{|c|c|c|c|c|c|c|c|}
\hline \multirow{2}{*}{\multicolumn{2}{|c|}{ Đặc điểm chung }} & \multicolumn{2}{|c|}{ GAD-7 $<\mathbf{1 0}$} & \multicolumn{2}{|c|}{ GAD-7 $\geq 10$} & \multirow{2}{*}{$\mathbf{p}$} & \multirow{2}{*}{ OR (95\%CI) } \\
\hline & & $n$ & $\%$ & $\mathbf{n}$ & $\%$ & & \\
\hline \multirow{2}{*}{ Tuổi } & $\leq 45$ & 9 & 90,0 & 1 & 10,0 & \multirow{2}{*}{0,003} & 1,059 \\
\hline & $>45$ & 102 & 89,5 & 12 & 10,5 & & $(0,123-9,097)$ \\
\hline \multirow{2}{*}{ Giới } & $\mathrm{Nam}$ & 79 & 87,8 & 11 & 12,2 & \multirow{2}{*}{0,304} & 0,449 \\
\hline & Nữ & 32 & 94,1 & 2 & 5,9 & & $(0,094-2,140)$ \\
\hline \multirow{2}{*}{$\begin{array}{l}\text { Thời gian chẩn } \\
\text { đoán }\end{array}$} & $\leq 24$ tháng & 104 & 89,7 & 12 & 10,3 & \multirow{2}{*}{0,037} & 1,238 \\
\hline & $>24$ tháng & 7 & 87,5 & 1 & 12,5 & & $(0,140-10,940)$ \\
\hline
\end{tabular}


Nhận xét: Nghiên cứu cho thấy có mối liên quan có ý nghĩa thống kê giữa lo âu với tuổi $(\mathrm{p}=$ $0,003 ; \mathrm{OR}=1,059,95 \% \mathrm{CI}=0,123-9,097)$ và thời gian chẩn đoán ung thư $(\mathrm{p}=0,037 ; \mathrm{OR}=1,238$, $95 \% \mathrm{CI}=0,140-10,940)$. Như vậy tuối trên 45 và thời gian chẩn đoán trên 24 tháng có tăng nguy cớ rối loạn lo âu.

\subsection{Mối liên quan giữa lo âu và vị trí ung thư'}

Bảng 3.3. Môi liên quan giứa lo âu và vị trí ung thư

\begin{tabular}{|c|c|c|c|c|c|c|}
\hline \multirow{2}{*}{ Vị trí ung thư } & \multicolumn{2}{|c|}{ GAD-7 $<10$} & \multicolumn{2}{|c|}{ GAD-7 $\geq 10$} & \multirow[b]{2}{*}{ p } & \multirow{2}{*}{ OR (95\%CI) } \\
\hline & $\mathbf{n}$ & $\%$ & $\mathbf{n}$ & $\%$ & & \\
\hline Thực quản & 31 & 91,2 & 3 & 8,8 & 0,711 & $1,292(0,333-5,008)$ \\
\hline Dạ dày & 20 & 80,0 & 5 & 20,0 & 0,082 & $0,352(0,104-1,188)$ \\
\hline Đại, trực tràng & 60 & 92,3 & 5 & 7,7 & 0,287 & $1,882(0,580-6,114)$ \\
\hline
\end{tabular}

Nhận xét: Nghiên cứu nhận thấy tỷ lệ lo âu gặp nhiều nhất ở ung thư dạ dày (20\% bệnh nhân có GAD-7 $\geq 10$ ), tỷ lệ lo âu ở ung thư thực quản và đại trực tràng xấp xỉ nhau (khoảng $8 \%$ ). Không có mối liên quan có ý nghĩa thống kê giữa lo âu và vị trí ung thư.

\subsection{Mối liên quan giữa lo âu và giai đoạn bệnh ung thư}

Bảng 3.4. Mối liên quan giữa lo âu và giai đoạn bệnh ung thư

\begin{tabular}{|c|c|c|c|c|c|c|}
\hline \multirow{2}{*}{$\begin{array}{l}\text { Giai đoạn bệnh ung } \\
\text { thư }\end{array}$} & \multicolumn{2}{|c|}{ GAD-7 $<10$} & \multicolumn{2}{|c|}{ GAD-7 $\geq 10$} & \multirow{2}{*}{$\mathbf{p}$} & \multirow{2}{*}{ OR $(95 \% C I)$} \\
\hline & $\mathbf{n}$ & $\%$ & $\mathbf{n}$ & $\%$ & & \\
\hline I & 13 & 100,0 & 0 & 0,0 & 0,192 & $1,133(1,058-1,212)$ \\
\hline II & 29 & 93,5 & 2 & 6,5 & 0,397 & $1,945(0,407-9,3030$ \\
\hline III & 57 & 85,1 & 10 & 14,9 & 0,080 & $0,317(0,083-1,213)$ \\
\hline IV & 12 & 92,3 & 1 & 7,7 & 0,728 & $1,455(0,174-12,193)$ \\
\hline
\end{tabular}

Nhận xét: Nghiên cứu nhận thây tỷ lệ lo âu cao nhất ở ung thư đường tiêu hóa giai đoạn III $(14,9 \%$ có GAD-7 $\geq 10)$ và IV $(7,7 \%)$, lo âu ở giai đoạn II chiếm $6,5 \%$ và không có bệnh nhân nào ở giai đoạn I có lo âu trên thang GAD-7. Không có mối liên quan có ý nghĩa thống kê giữa lo âu với giai đoạn bệnh ung thư.

\section{BÀN LUÂN}

4.1. Đặc điểm chung của nhóm đối tượng nghiên cứu. Trong 124 bệnh nhân nghiên cứu có $72,6 \%$ bệnh nhân nam, tỷ lệ nam/nữ xấp xỉ 2,6. Tuổi trung bình của đối tượng nghiên cứu là 57,9 , phần lớn có trình độ dưới lớp $10(57,3 \%)$ và độc thân/ góa $(93,5 \%)$. Loại ung thư đường tiêu hóa thường gặp nhất là đại trực tràng (chiếm 52,4\%), tiếp theo là ung thư thực quản $(27,4 \%)$ và dạ dày $(20,2 \%)$. Đa số bệnh nhân ở giai đoạn III-IV (chiếm 64,5\%). Điểm trung bình GAD-7 là 3,5 \pm 4,66 với 30,6\% bệnh nhân có lo âu. Kết quả nghiên cứu này phù hợp với nghiên cứu của Matsushita nhận thấy đa số bệnh nhân ung thư tiêu hóa là nam $(62,4 \%)$, tuổi trung bình là 68 [6]. Nghiên cứu của Tavoli cũng cho thấy ung thư tiêu hóa thường gặp nhất lần lượt là đại trực tràng $(55,8 \%)$ và $47,2 \%$ bệnh nhân có lio âu [7].

4.2. Mối liên quan giữa lo âu và đăc điểm chung. Nghiên cứu cho thấy có mối liển quan có ý nghĩa thống kê giữa lo âu với tuổi (p $=0,003 ; \mathrm{OR}=1,059,95 \% \mathrm{CI}=0,123-9,097)$ và thời gian chẩn đoán ung thư $(\mathrm{p}=0,037 ; \mathrm{OR}=$ $1,238,95 \%$ CI $=0,140-10,940)$. Như vậy tuổi trên 45 và thời gian chẩn đoán trên 24 tháng có tăng nguy cơ rối loạn lo âu. Kết quả này có sự khác biệt với nghiên cứu của Matsushita nhận thấy bệnh nhân ung thư tiêu hóa tuổi trẻ có nguy cớ lo âu cao hơn [6], có thể do ung thư tiêu hóa ở nước ta chủ yếu được phát hiện ở giai đoạn muộn, thường ở lứa tuổi trung niên với khả năng vượt qua stress kém hơn người trẻ. Hơn nữa, thời gian điêuu trị bênh kéo dài cũng là một yếu tố căng thẳng có thể khởi phát lo âu.

4.3. Mối liên quan giữa lo âu và vị trí ung thư. Nghiên cứu nhận thấy tỷ lệ lo âu gặp nhiều nhất ở ung thư dạ dày ( $20 \%$ bệnh nhân có GAD-7 $\geq 10$ ), tỷ lệ lo âu ở ung thư thực quản và đại trực tràng xấp xỉ nhau (khoảng $8 \%$ ). Không có mối liên quan có ý nghĩa thống kê giữa lo âu và vị trí ung thư. Kết quả này phù hợp với nghiên cứu của Medeiros cho thấy không có mối liên quan giữa lo âu và vị trí ung thư đại trực tràng [8]. Nghiên cứu của Lijuan nhận thấy bệnh nhân ung thư dạ dày có nguy cơ lo âu cao hơon [5], tuy nhiên thực hiện với đối tượng trước mồ nên kết quả khác biệt với nghiên cứu của chúng tôi tiến hành trên nhóm bệnh nhân ung thư tiêu hóa nói chung.

4.3. Mối liên quan giữa lo âu và giai đoạn bệnh ung thư. Nghiên cứu nhận thấy tỷ lệ lo âu cao nhất ở ung thư đường tiêu hóa giai đoạn III $(14,9 \%$ có GAD-7 $\geq 10)$ và IV $(7,7 \%)$, lo âu ở giai đoạn II chiếm $6,5 \%$ và không có bệnh nhân nào ở giai đoạn I có lo âu trên thang 
GAD-7. Không có mối liên quan có ý nghĩa thống kê giữa lo âu với giai đoạn bệnh ung thư. Nghiên cứu của Medeiros cũng cho thấy tỷ lệ ung thư giai đoạn III là phổ biến nhất nhưng không có mối liên quan giữa giai đoạn bệnh và lo âu [8]. Tuy nhiên, dù ở giai đoạn nào thì người bệnh ung thư đường tiêu hóa cũng có nguy cơ mắc lo âu do gánh nặng bệnh tật và suy giảm thể chất, do vậy chăm sóc bệnh nhân ung thư đường tiêu hóa cân chú ý nhận biết lo âu để can thiệp kịp thời, nhằm tăng hiệu quả điều trị và chất lượng sống cho bệnh nhân.

\section{KẾT LUẦN}

Nghiên cứu 124 bệnh nhân ung thư đường tiêu hóa tại Bệnh viện $K$ từ tháng 8/2020 đến 10/2020 chúng tôi có nhận xét sau: Đa số bệnh nhân là nam giới, tuổi trung niên. Theo thang GAD-7, có $30,6 \%$ bệnh nhân ung thư tiêu hóa có lo âu, nhiều nhất ở ung thư dạ dày và giai đoạn III-IV. Có mối liên quan có ý nghĩa thống kê giữa lo âu với tuổi và thời gian chẩn đoán bệnh. Không có mối liên quan giữa lo âu với vị trí và giai đoạn ung thứ.
TÀI LIỆU THAM KHẢO

1. International Agency for Research on Cancer W.H.O. (2020). Vietnam fact sheets. Globocan 2020.

2. (2012). NCCN Clinical Practice Guidelines in Oncology

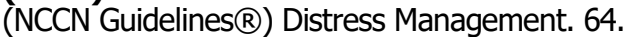

3. Holland J.C., Golant M., Greenberg D.B. và cô̂ng sự. Psycho-Oncology: A Quick Reference on the Psychosocial Dimensions of Cancer Symptom Management. 249.

4. Bektas D.K. và Demir S. (2016). Anxiety, Depression Levels and Quality of Life in Patients with Gastrointestinal Cancer in Turkey. Asian Pacific Journal of Cancer Prevention, 17(2), 723-731.

5. Han L. (2020). Prevalence, risk factors and prognostic role of anxiety and depression in surgical gastric cancer patients. Translational Cancer Research, 9(3).

6. Matsushita T., Matsushima E., và Maruyama M. (2005). Anxiety and depression of patients with digestive cancer. Psychiatry Clin Neurosci, 59(5), 576-583.

7. Tavoli A., Mohagheghi M.A., Montazeri A. và cộng sự. (2007). Anxiety and depression in patients with gastrointestinal cancer: does knowledge of cancer diagnosis matter?. BMC Gastroenterol, 7, 28.

8. Medeiros M., Oshima C.T.F., và Forones N.M. (2010). Depression and anxiety in colorecta cancer patients. J Gastrointest Cancer, 41(3), 179-184.

\section{CHI PHÍ TRỰC TIẾP ĐIỀU TRỊ UNG THƯ VÚ TẠI VIÊTT NAM, NĂM 2019}

\section{TÓM TẮT}

Mục tiêu: Nghiên cứu được thực hiện nhằm đo lường chi phí trực tiếp điều trị ung thư vú tại Viêt Nam năm 2019. Phương pháp nghiên cứu: N̉ghiển cứu mô tả cắt ngang, dưa trên hồi cứu số liệu từ hồ sơ thanh toán khi ra viện và phỏng vấn 87 người bệnh ung thư vú hoàn thành đợt điều trị trong thới gian thu thập số liệu của nghiên cứu, từ tháng 12/2019 đến tháng 6/2020 tại bệnh viện $K$ Trung Ương. Kết quả và kết luận: Nghiển cứu cho thấy, đợt điều trị hiện tại, tổng chi phí trực tiếp điều trị ung thư vú vào khoảng 17.657.000 VNĐ với chi phí thấp nhất là 3.188.000 VNĐ và chi phí cao nhất là 85.529.000 VNĐ. Đối với tổng chi phí trong năm 2019, tổng chi phí trực tiếp trung bình lên đến tổng chi phí trực tiếp vào khoảng 135.289.000 VNĐ với chi phí thấp nhất là 3.188.000 VNĐ và chi phí cao nhất là 923.221.000 VNĐ. Trong các nhóm chi phí, chi phí tiền túi hộ gia đình đều chiếm tỷ trọng lớn hớn.

*Trường Đại học Y tế Công Cộng

Chịu trách nhiệm chính: Nguyễn Quỳnh Anh

Email: nqa@huph.edu.vn

Ngày nhận bài: 2.3.2021

Ngày phản biên khoa hoc: 26.4 .2021

Ngày duyệt bài: 10.5.2021

\section{Nguyễn Quỳnh Anh*, Nguyễn Thu Hà*}

Tư khoá: Chi phí điều trị trực tiếp, ung thư vú, Việt Nam

\section{SUMMARY \\ DIRECT COST OF BREAST CANCER TREATMENT IN VIETNAM, 2019}

Objective: To measure the direct cost of breast cancer treatment in Vietnam in 2019. Methods: Cross-sectional descriptive study, based on retrospective billing data from hospital discharge records and interviews with 87 breast cancer patients who completed treatment during data collection of the study, from December 2019 to June 2020 at Vietnam National Cancer Hospital. Results and conclusions: During the current treatment, the total direct cost was about 17,657,000 VND with the lowest cost of $3,188,000$ VND and the highest cost of $85,529,000$ VND. For total costs in 2019, the average total direct costs amount to VND 135,289,000 with the lowest cost of VND $3,188,000$ and the highest cost of VND $923,221,000$. Among the cost groups, household outof-pocket expenses accounted for a larger share.

Keywords: Direct treatment costs, breast cancer, Vietnam

\section{I. ĐẶT VẤN ĐỀ}

Sự gia tăng của bệnh ung thư cùng với thực 